\title{
Mesoporous $\mathrm{ZrO}_{2}$ Nanopowder Catalysts for the Synthesis of 5-Hydroxymethylfurfural
}

Yumeng Zhouł, Lijing Zhang ${ }^{\dagger}$, Shengyang Tao ${ }^{\dagger}$ *

$\dagger$. Department of Chemistry, Dalian University of Technology, Dalian 116024, Liaoning, P.R. China.

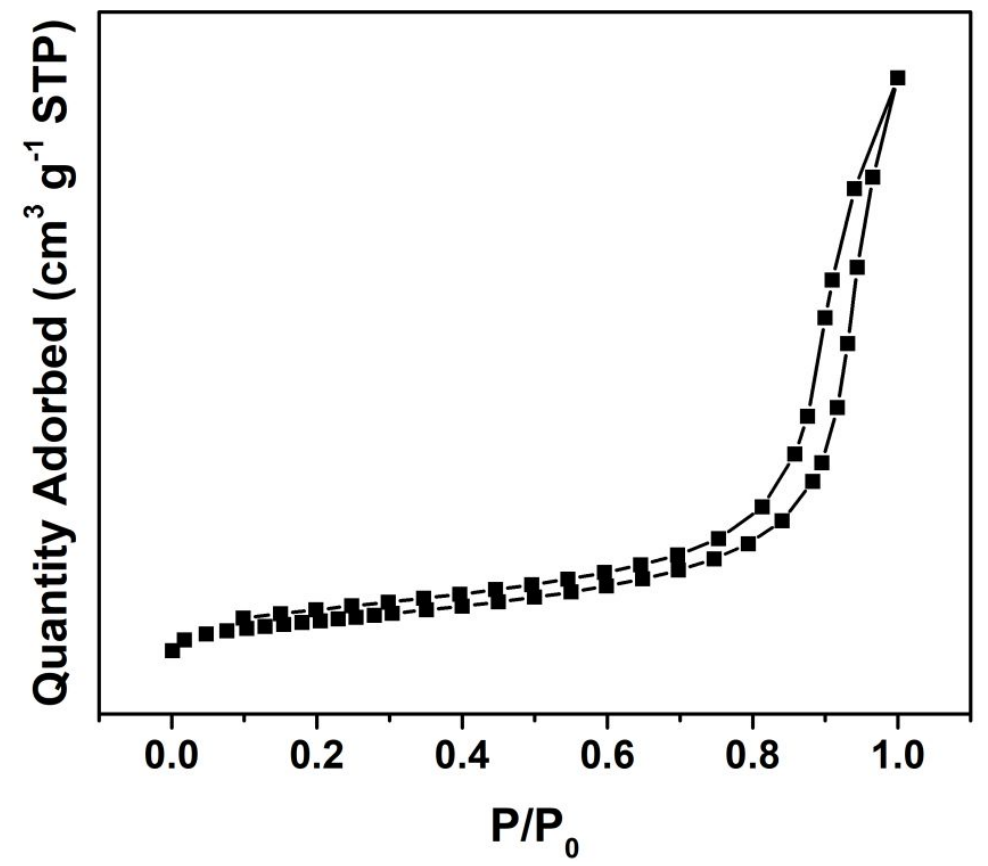

Figure S1. $\mathrm{N}_{2}$ adsorption-desorption isotherms of HPS. 


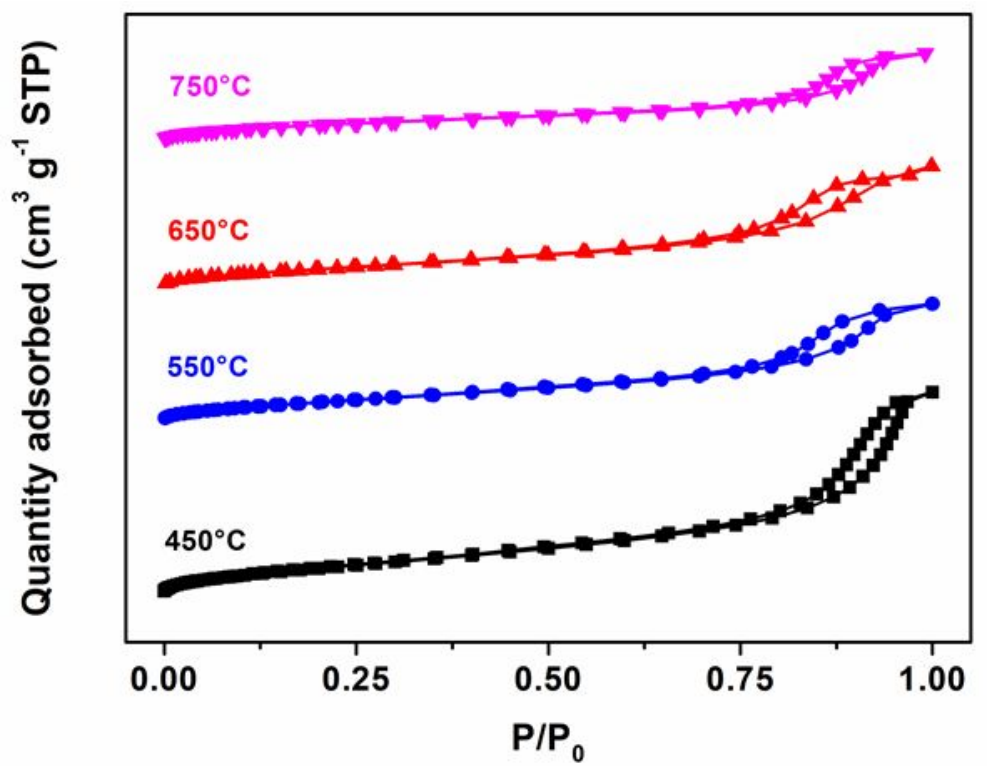

Figure S2. $\mathrm{N}_{2}$ adsorption-desorption isotherms of $\mathrm{ZrO}_{2}$ samples calcined at different temperature $\left(450{ }^{\circ} \mathrm{C}, 550^{\circ} \mathrm{C}, 650^{\circ} \mathrm{C}\right.$, and $\left.750^{\circ} \mathrm{C}\right)$.

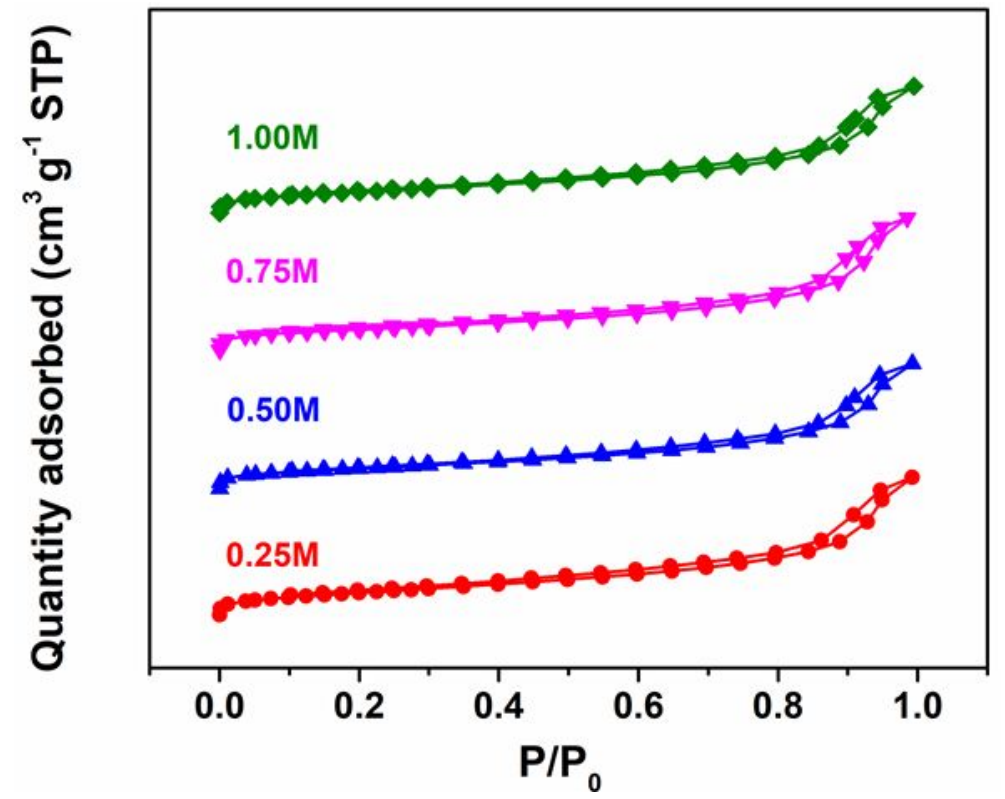

Figure S3. $\mathrm{N}_{2}$ adsorption-desorption isotherms of different sulfate $\mathrm{ZrO}_{2}$ samples $\left(0.25 \mathrm{M}-\mathrm{ZrO}_{2} / \mathrm{SO}_{4}{ }^{2-}, 0.50 \mathrm{M}-\mathrm{ZrO}_{2} / \mathrm{SO}_{4}{ }^{2-}, 0.75 \mathrm{M}-\mathrm{ZrO}_{2} / \mathrm{SO}_{4}{ }^{2-}\right)$. 


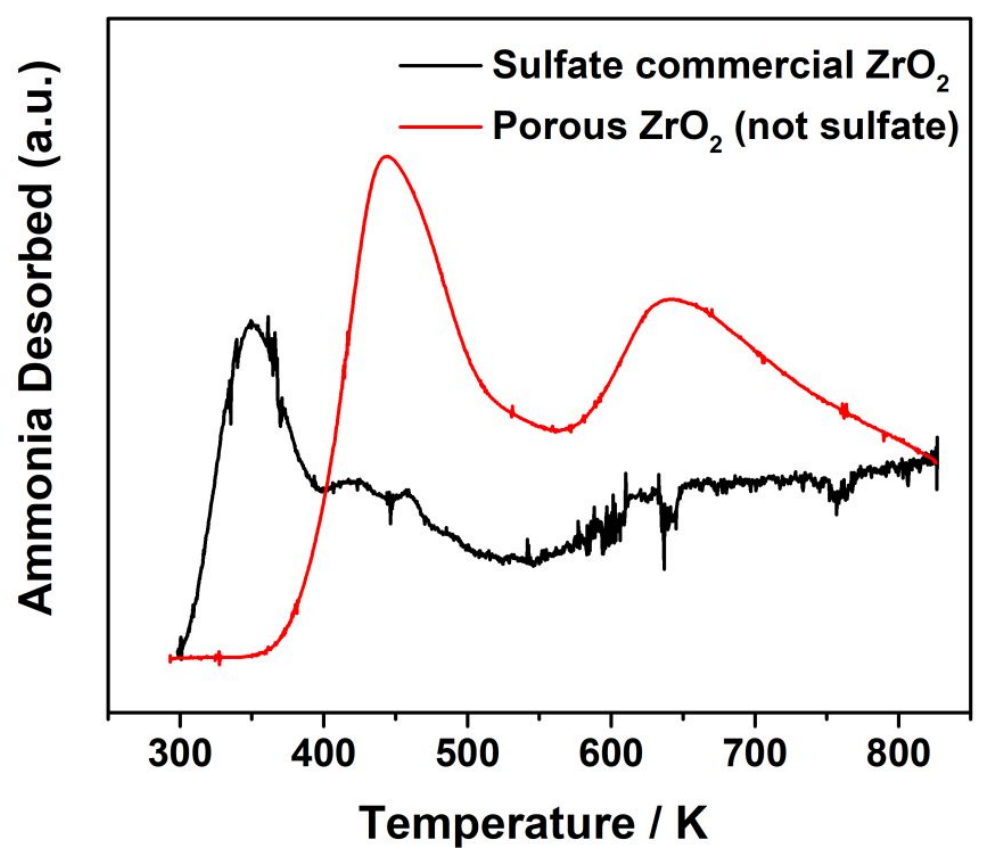

Figure S4. $\mathrm{NH}_{3}$-TPD curve of sulfate commercial $\mathrm{ZrO}_{2}$ and porous $\mathrm{ZrO}_{2}$.

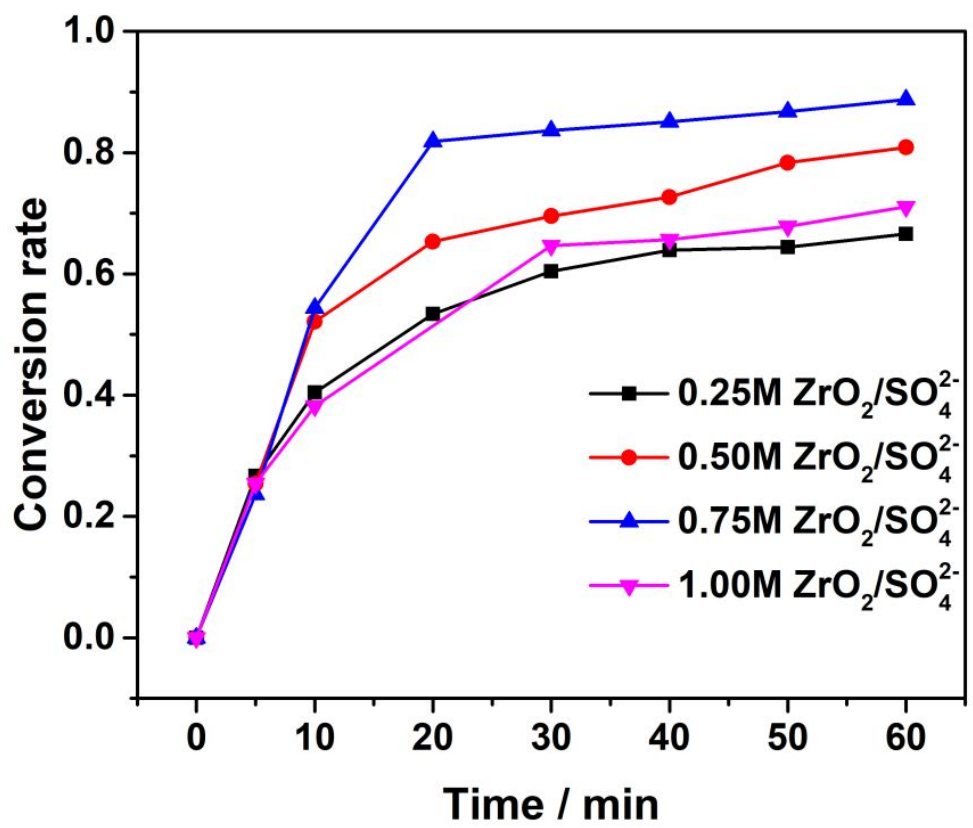

Figure S5. The conversion of the dehydration reaction by different catalysts. Reaction conditions: D-fructose $100 \mathrm{mg}$, catalyst $50 \mathrm{mg}$ and DMSO $10 \mathrm{ml}$ at $120^{\circ} \mathrm{C}$ for $60 \mathrm{~min}$. 